\title{
AS CONTRIBUIÇÕES DO BRINCAR AO DESENVOLVIMENTO EMOCIONAL DA CRIANÇA TÍMIDA NA EDUCAÇÃO INFANTIL
}

\author{
Michele da Silva Carlos ${ }^{1}$, Viviane Barrozo Manfré2 ${ }^{2}$ Andreia Cristiane Silva Wiezzel ${ }^{3}$ \\ ${ }^{1}$ Graduanda em Pedagogia pela Universidade Estadual Paulista - UNESP/ Presidente Prudente, SP. Bolsista de iniciação científica PIBIC/CNPq. E- \\ mail: micheledasilvacarlos@gmail.com Agência de fomento: PIBIC/CNPq \\ ${ }^{2}$ Graduanda em Pedagogia pela Universidade Estadual Paulista - UNESP/ Presidente Prudente, SP. Bolsista de iniciação científica PIBIC/CNPq. \\ ${ }^{3}$ Doutora em Educação pela Universidade Estadual Paulista - UNESP/Marília. Professora do Departamento de Educação da Universidade Estadual \\ Paulista - UNESP/ Presidente Prudente, SP.
}

\section{RESUMO}

A pesquisa em questão enfoca tema comum a socialização na educação infantil, especificamente, a timidez. Por meio da pesquisa busca-se proporcionar à criança o acesso ao brincar e aos benefícios desta atividade ao seu desenvolvimento emocional, levando a um amadurecimento das relações sociais. $O$ trabalho é desenvolvido sob forma de pesquisa qualitativa de tipo estudo de caso. Como instrumentos de coleta de dados são utilizadas observações, entrevistas com pais e professores e atividades lúdicas com a criança participante do projeto. A análise dos resultados parciais indica que a criança está utilizando a atividade lúdica como uma transição entre a fantasia e a realidade, trabalhando as ideias e interações entre esses dois mundos.

Palavras-chave: brincar, desenvolvimento emocional, timidez, brinquedoteca, criança.

\section{THE CONTRIBUTIONS OF THE PLAY RETRAIDA CHILD EMOTIONAL DEVELOPMENT IN EARLY CHILDHOOD EDUCATION}

\begin{abstract}
The project in question focuses on children who present difficulty common to socialization in early childhood education, specifically, children involving shyness. Through the research seeks to provide children access to the play and to the benefits of this activity to your emotional development, thus leading to a maturing social relation. The work is developed in the form of qualitative research case study type. As data collection instruments are used observations, interviews with parents and teachers and fun activities with the child project. The analysis of partial results indicates that the child is using the playful activity as a transition between fantasy and reality, working the ideas and interactions between these two worlds.
\end{abstract}

Keywords: play, emotional development, shyness, playroom, child.

\section{INTRODUÇÃO}

A pesquisa tem a finalidade de contribuir com os estudos relacionados a manifestações da timidez em crianças da educação infantil, tratando-se de um caso específico de uma criança de três anos de idade. Como a timidez possui um caráter afetivo ela pode ser desenvolvida no sujeito de modo positivo ou negativo. Quando manifestada de modo negativo pode prejudicar o desenvolvimento do sujeito nos aspectos sociais e afetivos, trazendo limitações para a sua vida. (CRAWFORD; TAYLOR, 2000).

Inúmeras vezes presencia-se pais ou até mesmo professores afirmando que a timidez é algo que faz parte do desenvolvimento da criança e que é questão de faixa etária. Também há situações em que os professores afirmam que crianças tímidas "são melhores", pois dão menos trabalho. Nessas ocasiões percebe-se a falta de conhecimento desses pais e professores, sendo fundamental que estes tenham um olhar atento a essas crianças, interagindo com elas de forma a contribuir às suas relações interpessoais.

Neste contexto não é possível desconsiderar o ambiente familiar nem o escolar, já que no primeiro ocorrem experiências e processos de aprendizagens diversos que constituem base ao desenvolvimento da capacidade de 
relacionamento e na escola a criança terá oportunidade de ampliar qualitativamente suas relações. Assim ambos os segmentos têm função educativa em prol do desenvolvimento da socialização da criança.

Segundo Crawford e Taylor (2000) a criança tímida tem grande medo de rejeição. Há um processo de pensamento negativo que faz o sujeito se concentrar nele mesmo, em oposição aos outros, não tendo autoconfiança. Tais características podem atrapalhar tanto $\mathrm{o}$ rendimento escolar quanto o desenvolvimento social, pois, muitas vezes os agentes que convivem com as crianças, por não compreenderem as necessidades afetivas que estão por trás da timidez, não percebem a necessidade de auxílio. A criança tímida é invisível aos olhos de professores, que as veem como crianças modelo, que não dão trabalho.

Outro ponto a destacar é que não raras vezes a escola exerce pouca vigilância contra maus tratos e às crianças que foram vítimas é dito que devem aprender a se defender e que isso as ajudará a enfrentar a vida. $O$ que geralmente acontece é que a criança acaba ficando mais dias sem ir à escola e cada vez menos capaz de enfrentar esta dificuldade (CRAWFORD; TAYLOR, 2000). Este contexto pode ser muito prejudicial à criança, pois esta ainda não sabe lidar com esses conflitos e, em um futuro próximo, pode ser vítima de um retraimento social, limitando suas relações com o grupo.

As autoras ainda destacam que crianças que são afastadas da mãe no nascimento ou que tiveram parto por cesariana também podem sofrer de sentimentos de isolamento e alienação. $\mathrm{Na}$ incubadora, os bebes não podem receber nenhum conforto nem assistência por parte de suas mães, por isso, podem não conseguir se aproximar das pessoas e ter sentimento de solidão (CRAWFORD; TAYLOR, 2000).

O desenvolvimento emocional é algo complexo e a maioria das dificuldades na infância podem não ser detectadas por um observador desatento, já que estas se concentram, em grande parte, no mundo interno da criança (WINNICOTT, 1982). Ao se pensar em crianças, deve-se considerar a complexidade que a vida representa para elas que precisam, desde 0 princípio, lidar com necessidades, sentimentos e impulsos extremamente fortes para o seu ego ainda em desenvolvimento.

A criança muitas vezes não compreende quando está passando por alguma dificuldade e não tem consciência do que está acontecendo a ela e o porquê. Nesse sentido o brincar aparece como possibilidade de manifestação de sentimentos, propiciando contato, expressão e até mesmo uma resolução daquilo que a incomoda.

Segundo Aberastury (1992) o brincar é tão importante ao desenvolvimento infantil que a sua ausência na vida da criança pode levar a transtornos emocionais ou ser resultado destes, podendo alterar o seu desenvolvimento emocional. Por isso é fundamental que o professor conheça a importância do brincar, de forma a inclui-lo na educação infantil, principalmente porque por meio dele é possível trabalhar com o desenvolvimento emocional da criança, o que irá auxiliar na qualidade de suas relações interpessoais em sala de aula.

Neste contexto o objetivo geral da pesquisa consiste em investigar e realizar intervenção com uma criança que, do ponto de vista da professora, apresenta dificuldade de relacionamento na escola, sobretudo timidez. Como objetivos específicos, busca-se: identificar dificuldades de relacionamento da criança em sala de aula; investigar as possíveis origens da timidez; promover ação de intervenção junto à criança, por meio de atividade lúdica e fornecer orientações às professoras e pais, caso haja interesse.

\section{METODOLOGIA}

O projeto é desenvolvido sob forma de pesquisa qualitativa de tipo estudo de caso. Segundo Neves (1996) a pesquisa qualitativa tem como fonte direta de dados o ambiente natural e o pesquisador é o instrumento fundamental. Este tipo de pesquisa tem caráter descritivo e o pesquisador se preocupa com os significados que as pessoas dão às coisas e à vida; tem um enfoque indutivo.

Conforme Godoy (1995) por meio da pesquisa qualitativa, um fenômeno pode ser compreendido dentro de um contexto, fazendo com que o pesquisador procure estudá-lo dentro das concepções dos indivíduos envolvidos, considerando-as relevantes. Desta forma vários dados podem ser coletados e diversos são os caminhos pelos quais a pesquisa qualitativa pode ser conduzida.

Como instrumentos de coleta de dados foram utilizadas entrevistas com os pais e professoras, observação da criança participante e atividades lúdicas com a mesma. As entrevistas 
possibilitaram a coleta de informações importantes acerca da criança no ambiente escolar e também familiar.

$\mathrm{Na}$ entrevista com as professoras (titular e auxiliar), especificamente, buscou-se identificar como se caracterizavam as relações interpessoais da criança, ou seja, como era a qualidade de sua interação com as demais crianças e com as professoras e como era seu desenvolvimento escolar.

A pesquisa foi iniciada no segundo semestre de 2016, sendo desenvolvida em uma Escola Municipal de Educação Infantil do interior de São Paulo-SP, que atende crianças em período integral. O projeto foi aprovado pelo Comitê de Ética em Pesquisa da FCT - UNESP (Processo no 045860/2014).

Os encontros foram realizados por meio do brincar espontâneo, uma vez por semana, em torno de 50 minutos. As atividades foram desenvolvidas na Brinquedoteca Escolar, que continha diversos brinquedos, tais como livros, bonecas, bonecos, "Lego", argolas, carrinhos, peças de montar, fantoches e uma casinha de madeira. Esses brinquedos eram acondicionados em duas caixas azuis em polipropileno.

\section{RESULTADOS}

Está participando do projeto uma criança da educação infantil, na faixa etária dos três anos: Gabriel $^{1}$. Nesta seção serão apresentados os resultados das entrevistas realizadas com o pai e as professoras, os encontros lúdicos e análise dos dados obtidos.

Com base na entrevista realizada com o pai, Gabriel é uma criança quieta e amorosa, a mãe é "mais rígida" e o pai é "bem tranquilo". Segundo o pai a mãe vê o filho quanto "tem folga", pois trabalha de segunda a domingo.

O relacionamento de Gabriel com a família, ainda conforme o pai, é bom. Por passar a maior parte do tempo sem ver os pais, quando há a oportunidade de estarem todos juntos, Gabriel só quer brincar e a atenção dos pais tem que ser toda voltada para ele. Quando os pais se cansam ou falam que não vão mais brincar, Gabriel fica muito irritado. As brincadeiras que mais gosta em casa são as que envolvem carrinhos, bonecos (Homem de ferro, Homem aranha), jogos de montar e de brincar com terra.

Em sala de aula, Gabriel tem uma participação bastante restrita em atividades coletivas e muitos

\footnotetext{
${ }^{1}$ Nome fictício.
}

de seus comportamentos demonstram a existência de dificuldade nas interações sociais, conforme pode ser observado no quadro a seguir, baseado em entrevista com a professora e observações:

Quadro 1. Descrição comportamental da criança

\begin{tabular}{|l|}
\hline Brinca sozinho \\
\hline Fala pouco e quando fala é muito baixo \\
\hline Não fica ao lado de pessoas desconhecidas \\
\hline Cha me manifesta quando alguma criança o agride \\
\hline Gosta de estar sempre ao lado da professora \\
\hline Não disputa um brinquedo que goste \\
\hline Evita olhar nos olhos das pessoas \\
\hline Relaciona-se pouco com seus pares \\
\hline Abaixa a cabeça quando alguém fala com ele \\
\hline É muito obediente \\
\hline Brinca com poucos brinquedos \\
\hline
\end{tabular}

Considerando esse conjunto de características iniciou-se a intervenção com a criança. As brincadeiras predominantes nos encontros foram: brincar de fazer comidinha, carrinho, desenhos e livros de histórias.

\section{DISCUSSÃO}

Com base nos encontros lúdicos realizados com a criança durante a pesquisa, foi possível verificar um avanço significativo nos relacionamentos sociais da criança. O brincar foi um instrumento fundamental neste contexto, pois, por meio deste, teve a oportunidade de elaborar seu conflito interno. Tal trajetória pode ser observada na análise apresentada a seguir.

No primeiro momento Gabriel estava com receio em conversar e até em pegar os brinquedos das caixas, por mais que estivesse sendo estimulado. Em um primeiro momento ele até aceitou ir à brinquedoteca, porém, uma vez estando lá, sentia medo em manipular os brinquedos. Quando foi feito o convite, ao final, para que ajudasse a guardar os brinquedos, continuava sem dizer nada, apenas observava estes sendo guardados.

Ao estimula-lo, abrindo as caixas, mostrando os brinquedos e dizendo que poderia brincar com e como quisesse, Gabriel foi perdendo o receio e criando confiança, a ponto de convidar a pesquisadora a participar de uma de suas brincadeiras. Esse convite mostrou que o garoto 
desejava interação e confiava na pesquisadora, passo muito importante em seu desenvolvimento social.

Tal convite aconteceu no momento em que ele estava brincando de fazer "comidinha". Fazendo uso de panelas e bule, disse que iria fazer café para a pesquisadora. Fez o café e a serviu no copo; os copos disponíveis eram nas cores rosa e roxo, mas ele sempre a servia no rosa, dizendo que rosa "era de mulher" e o copo roxo "era de homem" - o qual ele denominava de "copo azul".

Para Aberastury (1992) as brincadeiras de alimentar pessoas ou bonecos, utilizando-se de panelinhas, copos, talheres, remete a experiências de perda e recuperação. Esse tipo de brincadeira começa por volta dos dois anos, momento em que a criança passa por situações em que precisa se separar dos pais, como, por exemplo, a iniciação à vida escolar.

Gabriel estava sentindo falta dos pais, com quem pouco tinha contato devido a uma rotina extenuante de trabalho. $\mathrm{O}$ seu brincar trouxe a experiência de perda e, também, de recuperação dos pais que cuidam dele.

Gabriel optou, também, por brincadeiras com carros, panelinhas e desenho. $O$ desenho, ainda para Aberastury (1992) seria uma forma de guardar na memória a imagem da mãe que aparece e desaparece na concepção da criança de três anos - idade de Gabriel - diminuindo sua angústia de separação/medo da perda. Em um dos encontros lúdicos ao ser solicitado para que ajudasse a guardar os brinquedos nas caixas lembrando-o sempre a pesquisadora que esta voltaria na semana seguinte - sua expressão facial mudou, parecia estar triste por parar de brincar.

Os encontros foram muito ricos, já que Gabriel pode sair de uma condição em que apenas manipulava brinquedos para usufruir daquilo que é função específica do brincar para Aberastury (1992, p.51): "elaborar as situações traumáticas".

Gabriel surpreendeu quando pegou os livros algo que até então não havia despertado o seu interesse - e pediu à pesquisadora para ler a ele. Seu pedido não se deu por meio do diálogo, mas por gestos e atitudes, ou seja, ele entregou o livro aberto na mão da pesquisadora, se sentou ao seu lado e ficou olhando para ela, como se estivesse a esperar. Em seguida ela o questionou: "Você quer que eu leia?" e embora Gabriel não tivesse respondido, realizou a leitura, pois a ela confiou à tarefa de auxiliá-lo.
Para Aberastury (1992) a luta contra a perda da imagem surge com o livro. Além disso pode ser percebida nas infinitas vezes que a criança pede para que o adulto repita as histórias e mostre os desenhos. Para além de brincar apenas na expressão de seus sentimentos, Gabriel já estava utilizando o brincar como forma de elaboração de angústia de perda.

Segundo o relato das professoras a criança se desenvolveu bastante com a pesquisa, está mais participativa nas aulas, se mostrando "mais aberta" às relações sociais. Inicialmente ficava sozinho, agora Gabriel está acompanhado de um ou dois colegas, algo que até então não era observado.

\section{CONCLUSÃO}

Tendo em vista o exposto conclui-se que a pesquisa está auxiliando Gabriel no desenvolvimento da confiança e na possibilidade de construir vínculos com outras pessoas. A atividade lúdica está permitindo a ele expressar e elaborar seus sentimentos por meio da ação.

De acordo com Aberastury (1992) a criança utiliza este recurso até chegar à adolescência, se despedindo não só dos brinquedos e de seu mundo lúdico, mas, também, de seu corpo de criança. Portanto, o brincar é uma atividade inerente à criança e de suma importância a seu desenvolvimento emocional, precisando ser estimulado na escola. Durante o brincar, por meio de observações, o professor tem oportunidade de conhecer a criança e, de posse de suas características, orienta-la, acolhê-la em seus momentos de dificuldade.

A atividade lúdica é um meio que a criança utiliza para que seja vista, reconhecida e amparada. Muitas vezes o brincar é utilizado como "tapa buraco" nas escolas ou como atividade para preencher algum tempo entre uma atividade ou outra, porém, diante de seu potencial poderia ser incluída com mais critérios na educação infantil. $O$ professores precisam estar cientes de que o momento lúdico é mais uma oportunidade de conhecerem e trabalharem com as crianças.

Não há a necessidade de que tais atividades sejam exageradamente planejadas, mas que às crianças seja oferecida a oportunidade, o acesso ao brincar, a experiência de brincar com outras crianças e de brincar apenas consigo mesmas. 0 brincar não necessita, a todo momento, de um objetivo pedagógico estrito, pois, assim, perderá algo do subjetivo, daquilo que a criança precisa 
para exercer o desenvolvimento e domínio da criatividade. A criança necessita de momentos em que esteja livre para transitar entre a fantasia e a realidade, trabalhar as ideias e interações entre esses dois mundos e a partir daí se constituir, crescer, amadurecer, se alimentar de sentimentos bons, digerir os ruins, enfim, dar um colorido ao seu mundo.

\section{REFERÊNCIAS}

ABERASTURY, Arminda. A criança e seus jogos. 2 ed. Porto Alegre: Artmed, 1992.

CRAWFORD, Lynne; TAYLOR, Linda. Timidez: esclarecendo suas dúvidas. São Paulo: Ágora, 2000.

GODOY, A. S. Pesquisa qualitativa: tipos fundamentais. Revista de Administração de Empresas, São Paulo, v.35, n.3, p. 20-29. mai./jun. 1995.

NEVES, J. L. Pesquisa qualitativa: características, usos e possibilidades. Caderno de Pesquisas em Administração, São Paulo, v.1, n. 3, 2o sem. 1996.

WINNICOTT, D. W. A criança e o seu mundo.6.ed. Rio de Janeiro: LTC, 1982.

Recebido para publicação em: 08/08/2017

Revisado em: 15/09/2017

Aceito em: 05/10/2017 